\title{
Frequently Asked Questions About Rule of Law Assistance (And Why Better Answers Matter) $\equiv$
}

\author{
Veronica L. Taylor*
}

Despite a voluminous 'lessons learned' literature, there is much that we do not understand about rule of law assistance. Conceptually it lacks clarity and in practice seems to proceed in the absence of rigorous empirical research and 'thick' descriptions of the institutional histories, reform politics and the legal and social cultures of the countries it targets. In 2007 the World Bank committed nearly $\$ 23$ billion in loans for 'Law \& Justice \& Public Administration' and allocated $\$ 424.5$ million to 'Rule of Law' programs. Other lenders and donors committed billions more. It is alarming to observe this level of spending - and so much national and multilateral policy being formed - on the basis of relatively superficial information.

Many academic colleagues, development practitioners, lawyers and policy-makers and students are troubled by the knowledge vacuum in rule of law assistance. Here I consider some of the genuine and persistent questions about its scope and effect. I suggest that we need to find better answers, for our own intellectual and practical purposes, but also for the citizens of developing and transitional economies, who are the intended 'beneficiaries' of much rule of law assistance.

\section{Q: Is 'rule of law' assistance new or is it just a new label for old activities?}

A : Some of both

Legal reform as a component of multilateral or bilateral development assistance is not new. However, the fall of the Berlin Wall signaled an emphatic 'turn to law' in multilateral and bilateral flows of finance, development aid and technical assistance to developing and transition economies. Beginning in Central and Eastern Europe but expanding rapidly to other regions, this 'new' wave of legal reform

* Dan Fenno Henderson Professor of Law and Director, Asian Law Center, University of Washington. 
was funded at dramatically higher levels than in previous decades. As a result, over the last two decades, the creation, diffusion and enforcement of law and legal institutions has become both a set of free-standing goals and a tool-kit for achieving other policy aims, such as resolving armed conflict, entrenching electoral democracy, restructuring public administration, igniting economic growth, strengthening market mechanisms or improving public health and education.

The 'rule of law assistance' experiment since 1989 poses several unresolved questions for legal scholars and practitioners. An old question is the extent to which a 'remade' local legal system can or should empower the state, rather than the citizenry. It reemerges as a new question in part because the 'developmental state' of the 1960s,70s and 80s is being transformed around the world. This has spurred recent critiques of development assistance that decry 'big project' support for states, because host states often subvert the projects or misappropriate the funding. These critics instead advocate 'bottom-up', small-scale reforms designed by local or grassroots stakeholders. The problem that this prescription poses for rule of law assistance is that all legal systems are plural, and even legal formalists in the world of rule of law assistance are beginning to acknowledge that developing and transitional legal systems have both state and non-state components.

'Bottom up' or civil society initiatives are well-suited to informal or alternative forms of justice. They can also be harnessed to monitor state institutions, but they are seldom capable of replacing them. No amount of 'market-strengthening' or funding of 'civil society organizations' (CSOs) can substitute for a state production of functioning laws, the judiciary, the procuracy, private and government lawyers and the legal educators who produce them. Even in places where the formal legal system has only the most tenuous legitimacy and competence - such as Afghanistan - shoring up the formal system is recognized as symbolically important, politically desirable and functionally necessary.

Rule of law assistance projects are often ambivalent about their state counterparts and so can oscillate between, for example, intense focus on the courts or on civil society organizations. What we need here is better integration of theories about how institutions are formed and function, as well as insights from the field of regulatory theory that explain how state and non-state actors monitor each other and share the regulatory burden within $21^{\text {st }}$ century economies. Looking at legal institution-building from the perspective of regulatory theory may help to resolve the paradox that credible commitments to civil society, such as upholding human rights, or access to justice, require engagement with, and by, state actors. 


\section{Q: H ave we learned lessons - do we do rule of law assistance better now than in the past? A : W ewould like to think so}

Rule of law assistance, both now and then, tends to over-promise and underperform. We should understand that even the best-resourced legal systems in the world are hard-pressed to meet conflicting goals such poverty alleviation, democratization, improved 'governance', strengthened 'human rights', minimal 'corruption', and universal 'access to justice'. Assuming that rule of law assistance can somehow reconcile the symbolic, distributive, punitive, bureaucratic and political faces of formal law in a development setting is a triumph of hope over experience. The balancing of legal needs and the calibration of distributive effects are political tasks that foreign interventions are neither well equipped to, nor legitimately able to, perform. We make the rule of law assistance task harder still by ignoring important late $20^{\text {th }}$ century debates about the limits of law in post-industrial societies and the negative social consequences that flow from legalization of ordinary life and juridification of disputes. Recognizing and applying such insights to rule of law assistance programming could be an important corrective to projects that present a western fictionalized ideal to legal environments in which there are no political, economic or social analogues.

A further weakness in rule of law assistance is our tendency to keep reaffirming simplified models of modernization: many legal reform projects remain animated by the idea that we are promoting linear, modern evolution or the perfection of the human (legal) condition. In practice this tends to mean that we treat rule of law assistance as if it were an engine permanently set to 'forward', when we have ample evidence that it is frequently in 'reverse'. The $20^{\text {th }}$ century legal histories of Ethiopia, Afghanistan, the Caucuses and Central Asia furnish many examples of how quickly law and legal institutions 'reformed' with donor assistance can stall, or can simply unravel when placed under political or economic pressure. If we had, in fact, learned this historical lesson, we might be more focused on sustainability of programming and legal reforms calibrated to what the local economy could realistically support. We might also more seriously consider the possible toxic effects of enormous surges of rule of law funding, followed by donors' sudden withdrawal or deceleration.

\section{Q: If rule of law assistance is essentially about development, does this not focus on forward momentum make sense?}

A : N ot entirely

Some scholars claim that we are now in a 'third moment' of law and development. They see a new paradigm of more nuanced interventions in developing and tran- 
sitional economies by rule of law lender and donors, with the potential for better development outcomes. This is an attractive assertion, but it is problematic.

First, where rule of law assistance is funded as a form of foreign aid, our working assumption should be that it shares some of the characteristics of its funding source. Lancaster argues persuasively that - at minimum - foreign aid in the $20^{\text {th }}$ century has had multiple main purposes: diplomatic (including security), developmental, humanitarian relief and commercial and to a lesser extent, cultural. ${ }^{1}$ Since the 1990s, she points to the rise of additional goals, specifically: promoting economic and social transitions (including legal reform), promoting democracy, addressing global issues, mitigating conflicts and managing post-conflict transitions. She suggests that foreign aid providers mix (and frequently obscure) these goals in their programming and that relative priorities shift over time and according to target country. Many of these goals, of course, directly or indirectly require legal change.

A better working hypothesis for the $21^{\text {st }}$ century might be that rule of law assistance has become decoupled from development (or at least from the US 'law and development' experience in the 1960 and 70s) in a number of important ways.

Increasingly we see rule of law assistance being been shaped by geo-politics and subsumed within diplomatic and security aims. Since 1999 we see a clear US political impetus for legal reform interventions ranging from post-conflict state building in Cambodia, Bosnia, Iraq and Afghanistan to support for allies such as Pakistan and Indonesia in the Bush Administration's 'war on terror'. These disparate activities are bracketed under 'rule of law assistance' but their developmental impacts are highly variable. Closer attention to the political dimensions and goals of rule of law assistance might temper our scholarly and practical evaluations of what constitutes 'development' or 'success' in the field.

An upswing in militarization of rule of law also acts as cleavage between 'law' and 'development'. Pacification and disarmament are generally understood to be preconditions for stable social development and economic growth. In the $21^{\text {st }}$ century, however, we see military and civilian rule of law assistance proceeding in parallel in a new location: pre-post-conflict settings. The military 'standing-up' of legal institutions such as police forces, prison systems, prosecutors' offices and courts in Iraq, Afghanistan, Timor Leste, the Solomon Islands, Somalia and Sudan is a standard activity. More controversial are the United States and allied Provisional Reconstruction Teams (PRTs) in Afghanistan and Iraq that confer with local leaders and communities about justice issues and offer legal reform resources. Militarized delivery of 'legal' projects should not be confused with medium to long-term 'developmental' tasks such as clarifying property rights, regulating the

\footnotetext{
${ }^{1}$ Carol Lancaster, For eign A id: D iplomacy, D evelopment, D omestic P olitics, 2006, p. 13.
} 
finance system or educating the next generation of legal professionals, but it is a rapidly institutionalizing pattern of rule of law assistance.

Rule of law assistance also continues apace for other non-development reasons, among them diplomatic, commercial and cultural. The last decade of Asiafocused legal reform projects sponsored by the Japanese government, for example, included assisting Vietnam and Cambodia with Code-drafting and establishing Japanese law centers at universities in Vietnam, Cambodia, Uzbekistan and Mongolia. While worthwhile endeavors that also advance Japan's national profile in these regions, they are only related to 'development' (however defined) in a fairly tenuous way.

Q: So if rule of law assistance has multiple goals, is it really distincive? I s this not more or less the same legal reform that we do at home?

A : N ot quite

It is often argued that rule of law assistance is simply the flip side of legal reforms done 'at home' albeit delivered to a transitional or developing system located behind the economic curve of developed economies. Put another way, 'We have regulation, they have rule of law assistance'. By this we mean that the United Kingdom, Australia, Canada or Japan and other new regulatory states carry out periodic, systematic legal reform and/or codification and harness non-state actors and new regulatory techniques to manage their economies and social conflicts. Rule of law assistance proceeds on the unspoken assumption that 'our' experiences of doing domestic legal reform can, and should, guide the design of 'their' rule of law assistance.

This idea that legal reform is essentially similar around the world is attractive and somewhat plausible. Lawyers, in particular, identify problems by applying analogous reasoning based on prior examples and reach solutions through either inductive or deductive projections based on what they already know. At the practical level, this translates into institutional design based on legal exports or 'transplants'.

But are legal reform concepts and techniques completely fungible and portable? Some new warning signs are visible. Legal systems and legal institutions of individual countries and regions develop in unique ways. Rule of law assistance, however, is often designed to be generic and assumed to have uniform effect. We are only just beginning to differentiate the goals and methods of rule of law assistance delivered in pre-post-conflict settings from what is desirable or achievable in stable middle-income countries.

The lack of precision and predictability in rule of law assistance is also attributable to a widespread lack of baseline research through which to develop 'thick' descriptions of the target legal system before we attempt the latest rule of law 
intervention. Econometric studies of how businesspeople perceive legal procedures, or how legal institutions' performance can be quantified (e.g., number of judges, number of new statutes, time taken to process legal documents) have been very much in vogue, but we have dramatically fewer socio-legal, anthropological or historical studies of, say, key actors in the legal system, path dependencies in legal reform, how legal system 'insiders' see the politics of system reform, and what ideas and/or ideologies shape the interpretation and application of laws and regulations within that system. Donors, it seems, are willing to pay extraordinary amounts of money to carry out rule of law reforms, but not to fund the foundational research that might allow us to test the probability - or otherwise - that the reforms and the ideas that drive them will actually work.

Part of our problem is the historical amnesia that afflicts progress-oriented reformers. Donor-side organizations are particularly vulnerable to failures of institutional memory, particularly where they have contracted out many of their legal technical assistance functions. Projects are performed and team members consult and move on, without nurturing long-term relationships with local counterparts, learning about changes in the target system or monitoring their own (donor) long-term plans and promises.

Our inability to project likely outcomes is also rooted in our ignorance of economic history, ours and theirs. Too often the designed legal reform is modeled on what 'works' in a postindustrial economy - a kind of 'best practice' projected backwards through space and time onto a much more fragile economic and political system. So, in Afghanistan, for example, a key institutional weakness is the competence and corruption of the judiciary. The postindustrial regulatory tool of choice might be a judicial code of ethics, coupled with mandated declarations of assets and monitoring and enforcement including investigation and dismissal as a sanction. A code of ethics is predicated on having a group of professionalized elites, whereas in Afghanistan, judges are not bound together. They share no uniform legal education or legal knowledge, have no shared identity and are divided by patronage networks, regional and ethnic rivalries, and diverse understandings of Islamic and secular jurisprudence. This issue here is not whether the Afghan judiciary is corrupt; but what regulatory tool is appropriate for the system's stage of development.

Finding appropriate reform and regulatory approaches in rule of law assistance requires us to 'remember' how our own western or postindustrial legal and regulatory institutions were formed. Legal history has been devalued in contemporary legal education in many countries, yet it is essential for understanding our own stories of national legal development. We have very few useful accounts of the multiple factors that brought new legal and regulatory institutions into being in the $20^{\text {th }}$ century in different countries. This is important, because in a rule of 
law assistance setting we are dispatching the foreign 'expert' who knows how to operate their own existing institutions, but is not the person who designed and built them. Or as one colleague puts it, 'Being a public prosecutor in the US is not an adequate preparation for being a Chief of Party and leading institutional reform in a developing country.'

A further limitation of the 'what works for us at home' approach is that it ignores national legal reforms and initiatives. We know much less than we should about how donor-assisted rule of law reform and national legal reform link together. In theory the donor activity is intended to spur endogenous reform and create financial and legal knowledge flows that are interdependent and mutually constitutive. In practice the picture is more complex: host governments appropriate and divert rule of law assistance, and also pursue national legal reform goals that undercut the norms and agreed goals of external rule of law assistance. At the same time, by emphasizing rule of law assistance, we may also be misleading ourselves about how much we actually stimulate legal reforms by host states.

Confronted with the problem of Chinese toxic milk products, for example, the rule of law response might be to fund opportunities for public interest litigation in order to provoke a regulatory response from the Chinese government. In a globalized economy, however, the more salient pressure may simply come from the market, such as the wave or 'No Chinese products sold here' signs now evident in Japanese supermarkets. Alternatively, looking at the hundreds of millions of donor dollars spent on judicial reform in Indonesia since 1997, for example, Jan Michiel Otto, has asked 'Are the Indonesians really so very influenced by donors?"2 The answer is that we simply do not know, because we seldom ask where donor-assisted legal reform fits within a matrix of other internal and external drivers of change, or what local interlocutors really think about particular donors and their projects.

Now, nearly two decades into the latest wave or 'moment' of rule of law assistance, might be a good time to start providing more substantive answers to these and other questions about the scope and effect of lender and donor funded legal reform worldwide.

\footnotetext{
${ }^{2}$ Professor of Law and Director, Van Vollenhoven Institute, Leiden University; personal communication to author.
} 